\title{
Study on the Performance of an Ultra High Temperature Ceramic Material
}

\author{
Xiumei $\mathrm{Wu}$ \\ School of Art Design, Jingdezhen Ceramic Institute, China
}

\begin{abstract}
With the development of technology and the requirements, the requirement on materials performance is more and higher in all walks of life. Especially in aerospace and other high-tech industries is more demanding materials with high temperature resistance, erosion resistance and other characteristics. Niobium alloy currently used in combustion chamber and $\mathrm{Cf} / \mathrm{SiC}$ ceramic matrix composites has been unable to meet the requirements of the new generation of aircraft. It studied the preparation conditions and performance of $\mathrm{Cf} / \mathrm{ZrC}-\mathrm{SiC}$ high temperature resistant ceramic matrix composite materials. It founds that the infiltration time is $360 \mathrm{~min}$, the infiltration temperature is $1700^{\circ} \mathrm{C}$, the samples in mechanical properties, thermal physical properties, anti erosion performance is very excellent.
\end{abstract}

KEYWORD: High temperature resistance; Ablation resistance; Ceramic matrix composite

\section{BACKGROUND}

At present, the high-tech development is very rapid, and the demand for materials is increasing. Especially, the application of aerospace field as the representative, they require the high temperature resistance, ablation resistance, high strength, high stiffness and high toughness etc. They also put forward higher requirements on the performance of the engine combustion chamber material. The material has high temperature resistance, high strength, low density and micro ablation characteristics (Zhang Xinghong et al, 2015). The niobium alloy combustion chamber and $\mathrm{Cf} / \mathrm{SiC}$ ceramic matrix composites combustion chamber cannot be more than $1800^{\circ} \mathrm{C}$ environment used for a long time. It has been unable to meet the needs of a new generation of aircraft development, so the development of new high temperature resistant material is imminent.

Ultra-high temperature ceramics is $\mathrm{ZrB} 2, \mathrm{TaC}$, $\mathrm{HfB}, \mathrm{HfB} 2, \mathrm{ZrC}$ and other high-melting (above $3000{ }^{\circ} \mathrm{C}$ ) transition metal compound-based composite ceramic system. In the ultra high temperature (above $2000^{\circ} \mathrm{C}$ ) and oxygen atmosphere of harsh environmental conditions can be used as usual, it has good physical and chemical stability. Mainly used for hypersonic missile, the thermal protection system of space shuttle vehicles, such as wing front, end cap and engine hot end. It is the best alternative of refractory metal, $\mathrm{C} / \mathrm{C}(\mathrm{C} / \mathrm{SiC})$. It is also the most promising materials in ultra high temperature field
(Ma Baoxia et al, 2013). This paper developed $\mathrm{Cf} / \mathrm{ZrC}$-SiC ultra high temperature ceramic matrix composites for the aerospace industry, and strives to break the technical problem.

\section{EXPERIMENTAL MATERIALS AND EXPERIMENTAL PROCEDURES}

Carbon fiber reinforced ceramic matrix composite material preparation method are general mud dipping hot pressing method, precursor conversion method, chemical vapor infiltration, and reactive melt infiltration method. Due to the reaction infiltration process with short process cycle, it suited for profiled component molding. And it also reflects the superiority in the low cost preparation of continuous fiber reinforced high temperature resistant ceramic matrix composites. This experiment adopts the reactive infiltration preparation of $\mathrm{Cf} / \mathrm{ZrC}-\mathrm{SiC}$ high temperature resistant ceramic matrix composite method.

\subsection{Experimental material}

The $\mathrm{t}$ high temperature resistance $\mathrm{Cf} / \mathrm{ZrC}-\mathrm{SiC}$ ceramic matrix composites materials were prepared by the reaction infiltration. It applied to the ceramic precursor, infiltrating metal and fiber. The main materials are applied to the ceramic precursor, infiltration metal and reinforcing fibers. The ceramic precursor is polycarbosilane (PCS) and phenolic resin. 
The infiltration metal is $\mathrm{Zi}-\mathrm{Si}$. The zirconium silicon is $10: 1$. The average diameter of the carbon fiber reinforced is $7 \mathrm{um}$.

\subsection{The experimental process}

The main process of this experiment is divided into two parts. The first part is the preparation of the $\mathrm{Cf} / \mathrm{C}-\mathrm{SiC}$ substrate. The second part is the reaction of the infiltration process. Preparation method of $\mathrm{Cf} / \mathrm{C}$-SiC substrate commonly used PIP method. It involves in fiber forming, impregnation of precursor solution, and high temperature cracking. The specific procedure is shown in Figure 1.

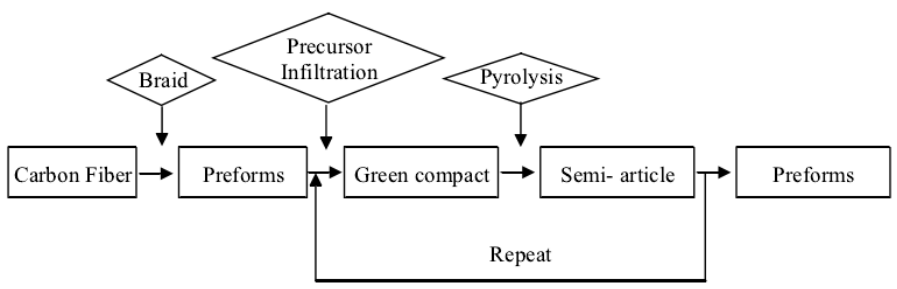

Figure 1 PIP preparation process chart

The substrate placed in a graphite crucible and alloy ingot placed on $\mathrm{Cf} / \mathrm{C}$-SiC substrate before the infiltration. It may ensure alloy excess according to the quality of free carbon in the substrate. The thermal insulated for a period of time, then cooling in the furnace. The diagram was shown in Figure 2.

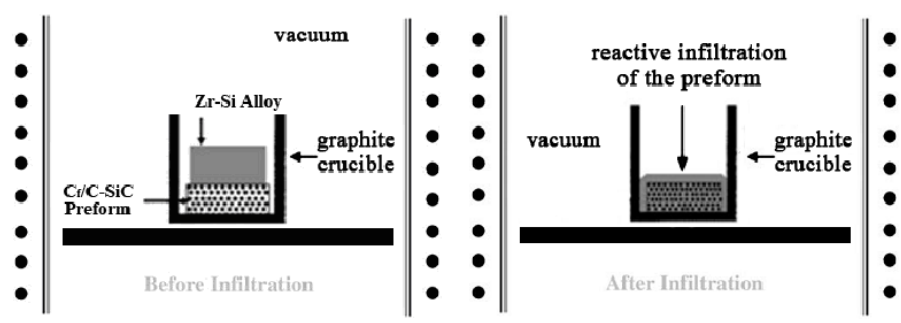

Figure 2 Infiltration process diagram

\section{CHARACTERIZATION METHOD}

\subsection{Mechanical properties test}

The bending strength and shear strength in universal material machine using three point bending method. In order to reduce the error, each data are measured in a sample of three and took the averaged. The principle is shown in Figure 3.

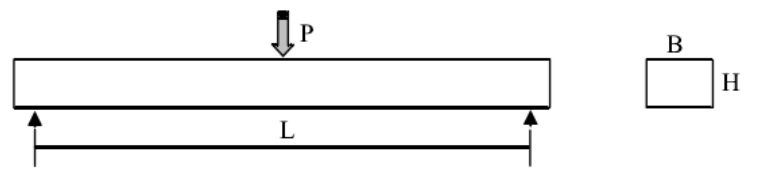

Figure 3 Schematic diagram of flexural strength test
The calculation formula for the flexural strength:

$\sigma_{b}=\frac{3 P L}{2 b h^{2}}$

In this formula: $\sigma b$ - three-point bending strength (Mpa);

$\mathrm{P}$ - the maximum load of fracture $(\mathrm{N})$;

L- span (mm);

b- specimen width ( $\mathrm{mm})$;

h- specimen height ( $\mathrm{mm})$.

The elastic modulus of $\mathrm{E}$ composites is calculated by the load displacement curve. The calculation formula is as follow:

$E=\frac{K L^{3}}{4 b h^{3}}$

$\mathrm{K}$ is the load displacement curve. Other parameters are as the formula (1).

\subsection{Determination of thermal physical properties}

The sample $\mathrm{Cf} / \mathrm{ZrC}$-SiC composite along the length direction parallel to the fiber processed into the size of $5 \mathrm{~mm} \times 5 \mathrm{~mm} \times 25 \mathrm{~mm}$. At the same time, it should to ensure the parallelism of both ends of the side. In the test, it used the small sample clamped at both ends. In the process of heating, it measured sample temperature coefficient of linear thermal expansion. The sample is cut into the diameter of $12.5 \mathrm{~mm}$, thickness of $3 \sim 4 \mathrm{~mm}$ size of the wafer. It used the laser pulse method to test composite thermal diffusion coefficient.

\subsection{Anti erosion performance test}

It tested the erosion resistance of samples according to the GJB 323A-96 standard. It used the oxyacetylene ablation method. The ablation resistance performance was showed as the material quality of material ablation rate and linear ablation rate. Figure 4 is a schematic diagram of the oxygen acetylene ablation experimental setup.

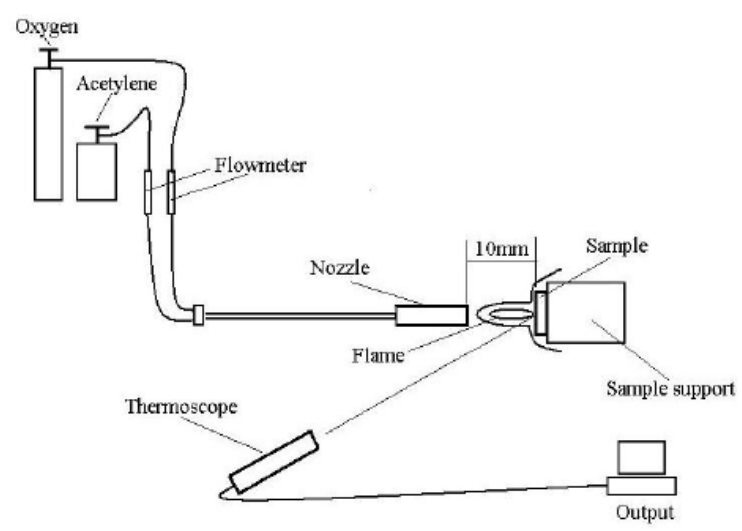

Figure 4 Schematic diagram of oxyacetylene ablation equipment 
The mass ablation rate refers to the quality of ablation in unit time sample amount. The calculation formula is as follow:

$M A=\frac{m_{0}-m_{1}}{t}$

In this formula: MA- mass ablation rate $(\mathrm{g} \cdot \mathrm{s}-1)$;

$\mathrm{m} 0$ - the sample quality before ablation $(\mathrm{g})$;

$\mathrm{ml}$ - the quality of specimen after ablation $(\mathrm{g})$;

$\mathrm{t}$ - the ablation time of assessment (s).

The linear ablation rate refers to the amount of ablation in the thickness direction at unit time. The calculation formula is as follow:

$R A=\frac{l_{0}-l_{1}}{t}$

In this formula: RA- linear ablation rate $(\mathrm{mm} \cdot \mathrm{s}-1)$;

10- the thickness of the specimen before ablation $(\mathrm{mm})$;

11- the thickness of the specimen after ablation $(\mathrm{mm})$;

$\mathrm{T}$ - the ablation time (s).

\section{RESULTS AND ANALYSIS}

\subsection{Study on mechanical properties of Cf/ZrC-SiC Composites}

This experiment studied the influence of infiltration temperature and infiltration time on mechanical properties of $\mathrm{Cf} / \mathrm{ZrC}-\mathrm{SiC}$ Composites. The results are shown in table 1 and table 2.

Table 1 The mechanical properties of different infiltration temperature $\mathrm{Cf} / \mathrm{ZrC}-\mathrm{SiC}$ materials

\begin{tabular}{llll}
\hline $\begin{array}{l}\text { Temperature } \\
/{ }^{\circ} \mathrm{C}\end{array}$ & \multirow{2}{*}{ Time/min } & $\begin{array}{l}\text { Flexural } \\
\text { Strength } / \mathrm{MPa}\end{array}$ & $\begin{array}{l}\text { Flexural Modu- } \\
\text { lus } / \mathrm{GPa}\end{array}$ \\
\hline 1600 & 120 & 100.76 & 32.78 \\
1700 & 120 & 106.83 & 46.63 \\
1800 & 120 & 103.52 & 32.12 \\
\hline
\end{tabular}

Table 2 The different infiltration time of mechanical properties $\mathrm{Cf} / \mathrm{ZrC}-\mathrm{SiC}$ materials

\begin{tabular}{llll}
\hline \multirow{2}{*}{ Time/min } & $\begin{array}{l}\text { Temperature } \\
/{ }^{\circ} \mathrm{C}\end{array}$ & $\begin{array}{l}\text { Flexural } \\
\text { Strength } / \mathrm{MPa}\end{array}$ & $\begin{array}{l}\text { Flexural } \\
\text { Modulus/GPa }\end{array}$ \\
\hline 60 & 1700 & 103.31 & 35.43 \\
120 & 1700 & 106.83 & 46.63 \\
240 & 1700 & 183.87 & 54.21 \\
360 & 1700 & 201.87 & 65.34 \\
\hline
\end{tabular}

With the increase of infiltration temperature, the bending strength of composites changed little. It was about $100 \mathrm{MPa}$. The bending modulus at $1700^{\circ} \mathrm{C}$ to obtain the maximum value which was $46.63 \mathrm{GPa}$. The $\mathrm{Cf} / \mathrm{ZrC}-\mathrm{SiC}$ composite three temperatures in the preparation process, a large number of $\mathrm{ZrC}$ matrix existed in fiber bundles. Base load transfer capacity decreased. There are pores in the matrix and fiber bundles, it weakened ability of resistance deformation. The bending properties of $\mathrm{Cf} / \mathrm{ZrC}-\mathrm{SiC}$ composites obtained were low (Wang Lingling et al, 2015).

The bending properties of $\mathrm{Cf} / \mathrm{ZrC}-\mathrm{SiC}$ materials with increasing melt infiltration time prolonged. When extended from $120 \mathrm{~min}$ to $240 \mathrm{~min}$, its performanice increased. Compared with the infiltration time is $240 \mathrm{~min}$, its performance slowdown when the infiltration time is extended to $360 \mathrm{~min}$. The infiltration time prolonged, it melt to impregnate fiber bundles and to improve the degree of dense material. It is also beneficial for its mechanical properties.

Comprehensive table 1 Table 2 shows that when the infiltration temperature is $1700^{\circ} \mathrm{C}$, the infiltration time is $6 \mathrm{~h}$, the flexural strength and flexural modulus of $\mathrm{Cf} / \mathrm{ZrC}-\mathrm{SiC}$ composites were $201.87 \mathrm{MPa}$ and 65.34GPa.

\subsection{Research on Thermophysical Properties of Cf/ZrC-SiC Composites}

$\mathrm{Cf} / \mathrm{ZrC}-\mathrm{SiC}$ composite is a new type of high temperature resistant ceramic matrix composites. This new material is mainly aimed at ultra high temperature field. So the research on the thermal properties of materials is the key technology whether this material can be used of some key components.

The thermal expansion coefficient is a key parameter to characterize the thermal stability. It affects the dimensional stability of components in the application. This experiment tested the expansion coefficient of the $\mathrm{Cf} / \mathrm{ZrC}-\mathrm{SiC}$ composite along the generatrix direction from room temperature to $1500^{\circ} \mathrm{C}$. Relationship between thermal expansion coefficients of $\mathrm{Cf} / \mathrm{ZrC}-\mathrm{SiC}$ composites with temperature was obtained. As shown in Figure 5.

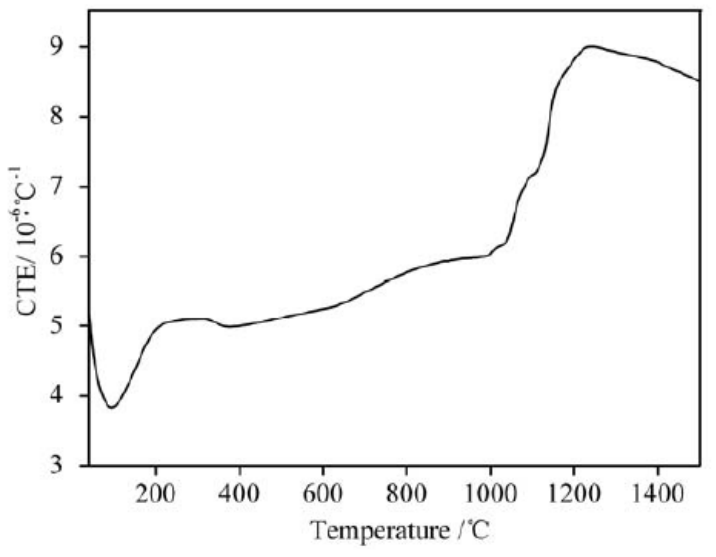

Figure 5 The relationship between $\mathrm{Cf} / \mathrm{ZrC}-\mathrm{SiC}$ composite thermal expansion coefficient and temperature

We can see that with the increase of temperature, the average value of material thermal expansion coefficient along the generatrix direction was increased, coupled with the remainder of alloy materi- 
als within the $\mathrm{Cf} / \mathrm{ZrC}$-SiC, so the measured thermal expansion coefficient greater.

Thermal diffusivity reflects the heat in the material transfer speed, and the temperature of each part of parametric representation of objects tends to consistent ability. In the same external heating or cooling conditions, the thermal diffusion coefficient is higher. The larger propagation velocity of the internal temperature, the temperature difference is smaller. The $\mathrm{Cf} / \mathrm{ZrC}-\mathrm{SiC}$ composite material at different temperatures the thermal diffusion coefficient is shown in Figure 6. The measured data using two polynomial fittings, it found that thermal diffusion coefficient changes with temperature showed a parabolic law well.

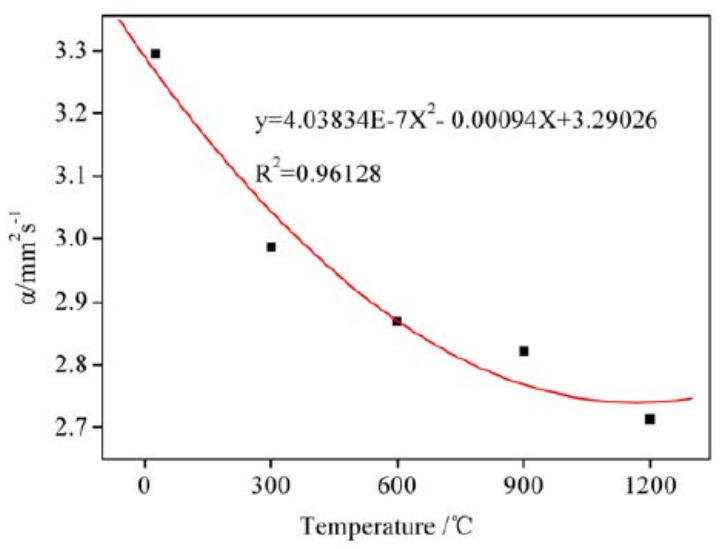

Figure $6 \mathrm{Cf} / \mathrm{ZrC}-\mathrm{SiC}$ composite thermal diffusion coefficient with the change of temperature

The thermal diffusion coefficient of the composites increased with temperature gradually decreased. In $600^{\circ} \mathrm{C}$, it decreased faster. It remained stable at $1200^{\circ} \mathrm{C}$. This is a principle that the anisotropic characteristics of $\mathrm{Cf} / \mathrm{ZrC}-\mathrm{SiC}$ composites, and the $\mathrm{Cf} / \mathrm{ZrC}-\mathrm{SiC}$ composite material internal temperature tends to be uniform under high temperature condition. It relieved internal heat stress, and improved the seismic performance of materials (Jin Hua et al, 2013).

\subsection{Study on anti ablation properties of $\mathrm{C} / \mathrm{ZrC}$-SiC composites}

Preparation of novel Cf/ZrC-SiC resistant ultra high temperature ceramic composite target is expansion of the application of $\mathrm{Cf} / \mathrm{SiC}$ materials the high temperature. So it studied on the anti erosion performance. According to GJB323-96A standard tests, the ablation resistance test materials used oxyacetylene ablation method. The performance comparison of common $\mathrm{Cf} / \mathrm{SiC}$ composite with anti ablation $\mathrm{Cf} / \mathrm{ZrC}-\mathrm{SiC}$ samples which infiltration temperature is 1700 and infiltration time is $360 \mathrm{~min}$ (Duan Liuyang et al, 2015). It was shown in table 3.
Table 3 The performance comparison of anti ablation $\mathrm{Cf} / \mathrm{ZrC}$ $\mathrm{SiC}$ samples with common $\mathrm{Cf} / \mathrm{SiC}$ composite

\begin{tabular}{llll}
\hline Sample & $\begin{array}{l}\text { Ablated } \\
\text { time } / \mathrm{s}\end{array}$ & $\begin{array}{l}\text { Mass loss } \\
\text { Rate } / \mathrm{g} / \mathrm{s}\end{array}$ & $\begin{array}{l}\text { Recession loss } \\
\text { Rate } / \mathrm{mm} / \mathrm{s}\end{array}$ \\
\hline $\mathrm{C}_{\mathrm{f}} / \mathrm{ZrC}-\mathrm{SiC}$ & 30 & 0.013 & 0.022 \\
$\mathrm{C}_{\mathrm{f}} / \mathrm{SiC}$ & 30 & 0.043 & 0.062 \\
\hline
\end{tabular}

Compared with $\mathrm{Cf} / \mathrm{SiC}$ composite, the ablation resistance of $\mathrm{Cf} / \mathrm{ZrC}-\mathrm{SiC}$ composites increased obviously. The mass ablation rate is reduced 4 times. The linear ablation rate is decreased 3 times. Composite ablation rate change is mainly caused by $\mathrm{SiO}_{2}$ melt and $\mathrm{ZrO}_{2}$ particles. $\mathrm{SiC}$ oxidized to form $\mathrm{SiO}_{2}$, it forms the glass melt under the low temperature. $\mathrm{SiO}_{2}$ glass has good fluidity. The flow in the surface oxide layer formed in the barrier layer to prevent oxidizing atmosphere. High temperature resistance of ceramic $\mathrm{ZrC}$ 's melting point up to $3540^{\circ} \mathrm{C}$ and the melting point of $\mathrm{ZrO}_{2}$ oxidation products at $2700^{\circ} \mathrm{C}$. In the environment of the scour erosion, $\mathrm{SiO}_{2}$ fluid on the molten state has certain pinning effect. It also reduced the melt viscosity of $\mathrm{SiO}_{2}$. The linear ablation rate and mass ablation rate compared to $\mathrm{Cf} / \mathrm{SiC}$ material decreased.

\section{CONCLUSION}

Study on preparation and properties of $\mathrm{Cf} / \mathrm{ZrC}-\mathrm{SiC}$ ceramic matrix composites, it can conclusion that: The mechanical properties of the samples is the best when the infiltration temperature is $1700^{\circ} \mathrm{C}$ and the infiltration time is $360 \mathrm{~min}$. $\mathrm{Cf} / \mathrm{ZrC}-\mathrm{SiC}$ ceramic matrix composite's thermal expansion coefficient with the increased of temperature raise. The thermal diffusion coefficient decreased gradually until stable, the temperature field inside the $\mathrm{Cf} / \mathrm{ZrC}$-SiC composite material tends to be uniform under the high temperature condition. It relieved internal heat stress, and improved the seismic performance of materials. Compared with the common $\mathrm{Cf} / \mathrm{SiC}$ composite, the ablation resistance of $\mathrm{Cf} / \mathrm{ZrC}-\mathrm{SiC}$ ceramic matrix composites improved.

\section{ACKNOWLEDGMENTS}

This paper is a case study of the National Nature and the times of the design of the social science planning project of Jiangxi Province in 2012 (12YS203); This paper also is the result of the research on the evolution of Jingdezhen ceramic art education from modern times to the modern times, which is the innovation center of the cultural heritage of Jingdezhen Ceramic Institute. 


\section{REFERENCES}

Duan Liuyang, Luo Lei, Wang Yiguang. Modification and Ablation of Ultra-high Temperature Ceramic Matrix Composites[J]. China Material Progress, 2015(10): 762-769.

Jin Hua, Meng Songhe, Xie Weihua, et al. Experimental Study on the Factors Affected the Performance of Ultra High Temperature Ceramic Composite Material Thermal Shock[J]. Journal of Solid Rocket Technology, 2013, 36(2): 255-260.

Ma Baoxia, Guo Erjun, Wang Liping. Research Progress of ZrC Ultra High Temperature Ceramic Composites[J]. Materials Review, 201327(3): 49-54.

Wang Lingling, Fang Guodong, Liang Jun. High Temperature Tensile Damage Behavior of ZrB2 Ultra High Temperature Ceramic Composites[J]. Acta Materiae Compositae Sinica, 2015, 32(1): 125-130.

Zhang Xinghong, Hu Ping, Han Jiecai, et al. Research Progress of Ultra High Temperature Ceramic Composites[J]. Chinese Science Bulletin, 2015(3): 257-266. 